\title{
Interrogantes sobre la relación hombre-mujer dentro del matrimonio en el siglo XVI a través de tres cartas de emigrantes radicados en México
}

\section{DAVID FERNANDEZ FERNANDEZ}

Me acerco a este tema con el respeto de la distancia, tanto temporal como psicológico-afectiva, así como con la cercanía del análisis y el acercamiento a lo femenino y a lo masculino a través de la experiencia vital, necesaria siempre para comprender el pasado, pero especialmente necesaria cuando queremos aprehender, entrar, en este complejo mundo de los valores, actitudes, pautas de comportamiento. Me anima la idea de encontrar en estas cartas huellas de la unicidad de cada persona, al mismo tiempo que reencontrar el sedimiento común fruto de la heredad de tiempos anteriores. La dialéctica creativa entre el molde social y la rebeldía personal encuentran siempre un espacio de crecimiento aunque sea en la marginalidad de lo establecido, en la marginalidad de la propia conciencia.

Partimos de la idea básica de que no sólo existe una infraestructura económica, sino también una infraestructura que abarca la dimensión espiritual de la persona, la sensibilidad, la conciencia, esa dimensión escondida del ser que hay que reconstruir mediante los fragmentos exteriorizados en hechos concretos. Y sobre todo negar la identificación que algunos historiadores hacen entre esta dimensión interior que tiene todo hombre por el hecho de ser hombre, y toda mujer por el hecho de ser mujer, con la superestructura ideológica tal como la concibe la historiografía marxista o todo modelo historiográfico que siga su método de análisis. Esa superestructura es el molde, la dimensión personal es la arcilla, una arcilla que se cuece en el horno de la Historia al calor de estructuras y acontecimientos, una arcilla que no siempre tiene los mismos ingredientes y que no siempre se somete a los moldes dispuestos. 
En fin, para entrar ya en materia, sólo decir que este artículo quiere ser un ensayo de diálogo con esas palabras escritas en la intimidad de una pareja y que por paradojas de la historia se han convertido en un testimonio vivo de lo personal y de lo social, saliendo del anonimato de lo cotidiano.

Vamos a analizar tres cartas que escribieron a sus respectivas esposas tres emigrantes españoles que se encontraban en México. El contenido de éstas es rico en datos para una profundización en diferentes aspectos de la mentalidad (1), pero nosotros vamos a centrar el tema en la relación hombre-mujer, más exactamente, esposo-esposa en la segunda mitad del siglo XVI: ¿cómo ve el emigrante a su mujer?, ¿qué cosmovisión ordena el comportamiento de cada uno de ellos respecto sus esposas?, ¿qué rol jugaba la mujer en el mecanismo social?, ¿se identifica siempre el papel social asignado con el lugar que ocupa en la intimidad del matrimonio? Demasiadas preguntas como para esperar una respuesta rotunda de estas tres cartas, pero, aunque sólo nos sirvan como interpelación para seguir preguntándonos, habrán cumplido su función de testimonio veraz de las contradicciones entre lo ideológico y lo cotidiano en la vida de las mujeres y de los hombres del siglo XVI.

Las cartas-reclamo acompañaban a algunas solicitudes de permiso de embarque para demostrar que algún pariente o paisano establecido en América iba a acoger al nuevo emigrante que deseaba marcharse de España. Hemos elegido estas cartas:

-De Sebastián de Montes de Oca a su mujer María de Fuentes, en Sevilla, con origen y fecha de México, 15.II.1563.

-De Luis de Illescas a su mujer Catalina Gutiérrez, en Jerez de la Frontera, México, 24.IX.1564.

-De Antonio de Blas a su mujer Leonor Bernal, en Sanlúcar, México, 1.XI.1566 (?) (2).

Para introducirnos en el contenido de las cartas creemos necesario reflexionar sobre la importancia del honor como clave interpretativa de la organización y articulación del entramado social. ¿Apariencia o realidad? Hay una evidente vinculación entre el honor y la riqueza, y

(1) En estos momentos estamos trabajando en un proyecto de investigación que aborda esas cuestiones: "Emigración legal a Indias en la época de los Austrias: análisis de las mentalidades a través de las cartas-reclamo".

(2) Las tres cartas han sido extraídas de OTTE, Enrique: Cartas privadas de emigrantes a Indias, 1540-1616.

Para el contenido completo de las cartas véase el anexo. 
entre ambos, concepto ideológico y ambición material, configuran un modo' de ser específico, un estilo de vida, un impregnarlo todo mediante este filtro mental que preserva el sistema establecido, que provoca la asimilación íntima de las pautas definidas como válidas por el contexto político, económico, social y cultural, Fijación de lo estructural en lo más íntimo. Uno-a es lo que se espera que él-ella sea, y no lo que es en sí mismo-a. Complicada maraña de hechos, intenciones y pensamientos. ¿Cómo distinguir si uno-a es lo que se espera de él-ella porque lo tiene introyectado en su ser más genuino, o porque es la única forma de ser socialmente, aunque realmente no se sea así? No es un trabalenguas. Es un intento de llegar más allá de la apariencia, a pesar de reconocer que como historiadores estamos muy limitados en ese terreno. Sólo quedan retazos de lo que fue. Aun así, sólo el riesgo nos puede acercar a una visión más completa de la realidad histórica.

Es en el barroco donde el honor extiende su dominio con fortale$\mathrm{za}$, pero en el siglo XVI su presencia en las relaciones interpersonales es ya causa de acontecimientos y definición de objetivos; configuración de un talante propio, aunque hasta el último tercio del siglo XVI la atmósfera fuera más relajada, menos rigorista. Por supuesto, este mundo, este ideal vertebrador, envuelve también la relación hombremujer, y concretamente, el papel de la mujer, en cuyo vientre depositaron el honor, pero no siempre la confianza. ¿Estuvo el hombre de la segunda mitad del siglo XVI tan obsesionado con el adulterio como lo estuvo el hombre del barroco?

Entremos en las cartas y sigamos preguntando:

-En 1566, Antonio de Blas escribe a su mujer Leonor Bernal, que estaba en Sanlúcar, reclamando su presencia y la de su hijo en tierras de México. El primer párrafo de la carta concentra la preocupación por la honra de forma tajante:

"y mira cómo venís, venid en compañía de un hombre casado, que vengáis mucho a vuestra honia, mira que en vos está mi vida y mi muerte, por eso, señora, abrid los ojos, mira que el día de hoy no hay mayor riqueza en el mundo que es la honra, mas yo estoy tan confiado de vos y satisfecho que lo haréis como quien vos sois".

La posición acomodada de Antonio de Blas se mide por el hecho de aconsejar a su mujer que "los primeros reales que gastarades sea en una negra, para que os sirva por el camino" y por la insistencia monótona de que su esposa se provea en España de todo lo necesario 
para poder vivir bien, "porque acá vale un ojo de la cara". Antonio repite hasta cinco veces el verbo "proveer" en distintos tiempos verbales (y esto sin contar las palabras empleadas que significan más o menos lo mismo). La carta enumera de forma minuciosa lo que Leonor debe llevar: bienes de calidad. Dos ideas inundan la carta: la honra y la necesidad de bienes para vivir con cierta holgura porque "y teniendo en casa lo que hubiéredes menester es la vida". Vida vinculada a posesiones; identificación lógica en el contexto socio-económico de la época. Espejo bastante preciso de la jerarquía de valores que prevalecía como armazón ideológico del sistema. Las prioridades quedan recogidas: lo aparente y lo material. Riqueza y honor definen el ser y la vida misma.

Hay pocas alusiones de afecto, lo cual no quiere decir que no existiera, pero desde luego aparece de forma subordinada: "mira que en vos está mi vida y mi muerte". Es decir, el honor. O bien: "Cada día se me hace un año hasta veros, porque en esta vida no tengo otro descanso sino a vos, ni tengo otro deseo". Descanso y deseo: función de la mujer.

-De 1564 es la carta de Luis de Illescas a su mujer Catalina Gutiérrez, residente en Jerez de la Frontera (México, 24.IX.1564). Es importante saber quién es el que escribe y desde dónde lo hace, no sólo en un sentido geográfico sino también en un sentido social. A pesar de las limitaciones de la información epistolar sobre el estrato social del remitente y la receptora (acudiendo a otras fuentes podríamos averiguarlo, pero no es éste el objetivo principal del artículo, por lo que nos sirve una mera aproximación al mismo), Luis dice bastantes cosas sobre él y su mujer. Deja abierto un hueco que nos permite entrever. Sabemos que es un emigrante que se ha arraigado en América y que elogia la vida allí frente a la miseria de España. Sus palabras le exigen a su mujer que vaya con sus hijos a tierras de México: "...habrá visto mi voluntad tan determinante de que se venga con toda su casa a esta tierra, porque yo no pienso de ir en mi vida a esa". Sin embargo, Catalina no parecía muy dispuesta a hacer ese viaje. Era reacia a ir donde estaba su esposo, ya fuera por miedo a un viaje tan largo y/o miedo al desarraigo. Un tercer aspecto podría ser la falta de afecto hacia su marido, el sentirse más libre teniéndolo a distancia, pero esto es sólo una posibilidad difícil de comprobar.

Los recursos de su esposo fueron la intransigencia y el utilizar el ejemplo ajeno para convencerla: "...hacer lo que yo digo, aunque se pierda todo, y vaya la soga tras el caldero, y no tomar otro parecer contrario al mío, y quemar la miseria que allá tendremos. $Y$ hacer lo 
que yo digo es muy a servicio de Dios, pues no creo sabe que es fingida su venida, pues ya conoce esta tierra lo que es poner por delante cómo ha de venir una sola mujer por caminos tan largos y con cargar tan pesada de hijos...". Para el trayecto le aconseja que busque buena compañía y hace una alusión ajena sobre los maridos que mandan a buscar por sus mujeres, que podría intepretarse como que el mismo lo haría si fuera menester.

La carta tiene un tono frío y distante. No tiene signos de afectividad. De nuevo podemos pensar en una falta de cariño, o bien que el carácter de él le impide manifestar lo que siente: "y como no soy amigo de lisonjas es toda acabado". Lo económico es el centro de la carta y lo que determina la exigencia de Luis hacia su esposa. La idea del honor, aunque de forma más vaga, aparece también perfilada: “...a esto respondo que para cuando uno ha de hacer su voluntad y poner por obra, todo se le hace a su voluntad y halla las cosas a su propósito y compañías. muy honradas, que hartos hombres envían por sus mujeres". La compañía; por supuesto, ha de ser honrada, o si no, el marido envía a alguien de confianza para proteger el honor de la esposa. Hasta ahora, la mujer se nos aparece incapacitada para velar por sí misma de su honra, que no es sino la honra del esposo proyectada sobre ella. Así lo ven al menos Luis de Illescas y Antonio de Blas.

-La tercera carta la escribe Sebastián de Montes de Oca. Está dirigida a su mujer María de Fuentes, en Sevilla (México, 15.II.1563). El esquema básico es el mismo: marido que reclama a su esposa para que vaya a reunirse con él. Sebastián le indica lo que tiene que hacer para "vender el tributo" y realizar el viaje. Es una carta emotiva y tierna donde el esposo expresa a su esposa que tiene "muy gran pena de la soledad y trabajos que ha pasado con mi ausencia, y así deseo mucho que ambos hagamos la voluntad de Dios y que estemos juntos como Dios lo manda". Lo importante, lo primero, es estar juntos, llevar juntos el peso de la vida. La separación es una separación no deseada, consecuencia de las circunstancias económicas. El pesimismo que trasluce la expresión "mísera vida" nos adentra en un estrato social más humilde y limitado económicamente que los dos emigrantes anteriores (Luis de Illescas estaría en un status intermedio entre el de Antonio de Blas y el de Sebastián de Montes de Oca). En esta ocasión, la primacía del honor y la comodidad que empapa la primera carta o la exaltación de la riqueza que fluye en la segunda, son desbancadas por la íntima relación de los dos cónyuges, de otra forma no se entendería el salto conceptual que da Sebastián haciendo de su 
mujer la valedora y defensora de su honra por lo que ella es en sí misma, sin depender de una tercera persona que la guarde y vigile:

"...que aunque andéis el mundo por la mar y por la tierra habéis de vivir aquel tiempo que Dios tiene ordenado, y busque compañía con quien venga, y si no hallare, venga sola, que mujer es para mirar por su honra..."

El sistema de valores se invierte. Confianza en su fidelidad. Confianza a pesar de lo peligroso del viaje para una mujer sola. Amor por delante de la apariencia.

El siguiente paso es más difícil sin contar con las cartas que en ellas escribieron. ¿Qué pensaban? ¿Qué sentían? ¿Cómo actuaban?

En el caso de Leonor Bernal, su esposo, después de dejar claro el tema de la honra, escribía, según hemos citado anteriormente, "mas yo estoy tan confiado de vos y satisfecho que lo haréis como quien vos sois". Ese "como quien vos sois", siguiendo la lógica de la exposición, identificaría a su esposa con su propia mentalidad. Su confianza se apoya en el hecho de saber que Leonor actuará como él dice y no cobija sospecha de contrariedad. En el caso de María, "venga sola, que mujer es para mirar por su honra..." se expresa una conciencia de individualidad de la mujer que no aparece en el primer ejemplo, donde la esposa se nos presenta como una prolongación del marido, sin vida propia. ¿Tenía la mujer casada conciencia de individualidad y especificidad más allá del rol social preestablecido que le tocaba ejercer por ser mujer? ¿En qué estrato social surge esa conciencia? ¿Cómo se expresó?...

Las limitaciones para el desenvolvimiento de esa conciencia eran muchas. Mariló Vigil (3), comentando la opinión de Alonso de Andrade, dice que "las mujeres deben guardarse con gran honestidad, y no tomarse ninguna libertad aunque sus maridos se la den, "porque los maridos deben hacer mucha confianza de sus mujeres y las mujeres guardar más recogimiento, cuanto ellos les dieren más licencia". El molde era estrecho y estaba bien afianzado. Si embargo, María, si no encontró compañía, debió tomar la libertad que le ofrecía su esposo. Parece ser que lo afectivo tenía más cabida cuando lo patrimonial era más bien escaso, es decir, en los ámbitos populares. Como dice Saavedra Fajardo "a los nobles pertenece el honor y al pueblo la libertad" (4).

(3) VIGIL, Mariló: La vida de las mujeres en los siglos XVI y XVI, Madrid, Editorial siglo veintiuno, 1986, pág. 142.

(4) MARAVALL, J.A.: Poder, honor y élites en el s. XVII, Madrid, Ed. siglo veintiuno, 1984, pág. 
De todas formas creemos que la mujer ofreció resistencia, al menos desde ciertos lugares sociales, en la medida de sus posibilidades "no muy sonora, pero si efectiva, a los hombres de su entorno" (5). Resistencia cotidiana, personal, no estructurada, pero no por ello menos fundamental.

\section{ANEXO DE LAS CARTAS}

*Sebastián de Montes de Oca a su mujer María de Fuentes, en Sevilla (México, 15.II.1563).

Muy deseada y querida señora:

El dulcísimo Jesús sea siempre con ella. Recibí su carta, con la cual holgué mucho, aunque tengo muy gran pena de la soledad y trabajos que ha pasado con mi ausencia, y así deseo mucho que ambos hagamos la voluntad de Dios y que estemos juntos como Dios lo manda, y que acabemos esta mísera vida en su santo servicio, y así, señora de mi corazón, vista la presente se venga en el primer navio que salga de Sanlúcar para este puerto de la Veracruz. Señora, el señor Juan Luis de Chaves le dará un poder para que venda el tributo y compre una turca de paño de la color que quisiere, y asimismo un sombrero grande y un capote negro, que estas tres ropas ha de menester para desde la Veracruz a México, y el señor Juan Luis le sacará una licencia y le concertará el flete por un poder que lleva mío, y asimismo le comprará el matalotaje y todo lo necesario para la venida, y mira, señora, que no sea bastante de esta vida a estorbarle su buena venida a esta ciudad de México, donde la quedo esperando, y mira, señora, que aunque andéis el mundo por la mar y por la tierra habéis de vivir aquel tiempo que Dios tiene ordenado, y busque compañía con quien venga, y si no hallare, venga sola, que mujer es para mirar por su honra, y que llegando a la Veracruz pregunte por Cristóbal Ortiz, carpintero, natural de Carmona él y su mujer, que él la hospedará en su casa, y me escribirá para que yo vaya por ella, y ceso y no de rogar a Dios que acabemos esta mísera vida en su santo servicio, y" desando su venida, de México, a quince de febrero de 1563 años, quedo con su deseo

Sebastián de Montes de OCa

(5) VIGIL, Mariló: op. cit, pág. 1. 
(A mi deseada señora mujer María de Fuentes, en casa de su cuñado Jerónimo de León, en canto de la iglesia de San Martín, es maestro de órganos, en Sevilla). (I.G. 2050).

"Luis de Illescas a su mujer Catalina Gutiérrez en Jerez de la Frontera. (México, 24.IX.1564).

Señora:

En la flota pasada escribí muy largo dando cuenta a sus cartas que con hartas pocas me hallé, y aún verá por ésta de como menos tuve en la flota que llegó a esta tierra, más no me maravillo de ello, porque muy cerca del puerto se perdieron las cuatro naos de ellas, las mejores, y así se perderían las cartas, no trato en esto más de que en las mías que tengo habrá visto mi voluntad tan determinadamente de que se venga con toda su casa a esta tierra, porque yo no pienso de ir en mi vida a esa, y esto hago por las causas ya dichas en las demás mías, y que no ponga por delante cosa que otra cosa lo impida, y que esa miseria que allá hay que lo dé por dos reales, aunque no sea más caudal para salir de allá hasta llegar al puerto de esta Nueva España, donde ya tengo dicho pienso morir, porque para mí no es ya caminos tan largos para esta miserable y poca vida, y así tengo determinado de dejar a mis hijos en tierras donde no aprieten tantas miserias como en esa, en que el día de hoy donde quiera hay un pedazo de mal camino y donde piensan hay tocinos, no hay estacas y al buen entendedor pocas palabras. Dígolo por las quejas de sus cartas y aún no bastaban, sino las demás de sus vecinos que no declaro, y así doy cuenta por las mías de cómo había comprado casas, y que me habían puesto en gran estrechura y dar causa de noenviar dineros, y no eran menester, sino hacer lo que yo digo, aunque se pierda todo, y vaya la soga tras el caldero, y no tomar otro parecer contrario al mío, y quemar la miseria que allá tendremos. Y hacer lo que yo digo es muy a servicio de Dios, pues no creo que es fingida su venida, pues ya conoce esta tierra lo que es poner por delante cómo ha de venir una sola mujer por caminos tan largos y con carga tan pesada de hijos, a esto respondo que para cuando uno ha de hacer su voluntad y halla las cosas a su propósito y compañías muy honradas, que hartos hombres envían por sus mujeres. Mi compadre Gaspar Melchor envía por su mujer y toda su casa, otros ciento que no declaro. No quiero ser más prolijo en todo, porque mucho más papel que éste era menester para declararme, sino 
encamine Dios, Nuestro Señor, aquello que para su santo servicio sea con que le sirvamos. De cosas particulares no trato, porque bastan mis congojas y no las ajenas, y como no soy amigo de lisonjas es todo acabado. Nuestro Señor dé su gracia y les dé buen viaje cuando sea menester a los sobre aguas de la mar se vean. Fecha en México, a 24 de setiembre de 1564 años.

Luis de Illescas

En esa ciudad vive una señora que se dice Isabel de Torres, mujer que fue de Simón de Vara, sastre, que es en gloria, recibe contento la visite, que están dos hijos suyos a mi cargo, que soy su tutor y guardador, y que me escriba del recibo de estas mias que en la flota envié. Sus hijos están muy buenos y a oficios uno de sastre, otro a calcetero, que es lo que a ellos pareció mejor de aprender.

(A la señora Catalina Gutiérrez, mujer de Luis de Illescas, en Jerez de la Frontera). (I.G.2050).

*Antonio de Blas a su mujer Leonor Bernal, en Sanlúcar. (México, 1.XI.1566 (?)).

Señora y mujer:

Vista ésta luego pone por obra de venir a esta tierra con el mensajero de ésta, que es mi hermano Yepes, y mira cómo venís, venid en compañía de un hombre casado, que vengáis mucho a vuestra honra, mira que en vos está mi vida y mi muerte, por eso, señora, abrid los ojos, mira que el día de hoy no hay mayor riqueza en el mundo que es la honra, más que yo estoy tan confiado de vos y satisfecho que lo haréis como quien vos sois.

Allí lleva el señor Yepes trescientos pesos, para que gastéis en lo que hubiéredes menester. Los primeros reales que gastáredes sea en una negra, para que os sirva por el camino, y vestíos vos muy bien, y mi hijo Antón Blas hacerle dos o tres vestidos, para que tenga que romper acá, y de todo lo que fuere menester para su casa venga proveida, porque acá vale todo muy caro. Todo el lienzo que pudiere traer traiga, porque a según vale acá es de balde en Castilla, y traiga mucho azafrán, y de toda especia, hasta hilo, y toda vuestra casa, y traeme un par de sillas jinetas, que sean tales, una para vos y otra para vuestro hijo, porque no las podéis excusar. Pra mí me trae para un 
vestido para sayo y capa y calzas, negro, y raso para un jubón, y si pudiéredes traer un pedazo de paño de Perpiñán ha de ser de lo muy bueno, porque para vestidos será bueno acá. Ya os tengo dicho de donde fuere paño, como sea bueno, y lienzo para proveimiento de vuestra casa. Trae todo lo que pudiéredes, porque acá vale un ojo de de la cara, y teniendo en casa lo que hibiéredes menester es la vida, por eso os aviso que vengáis proveida. Cada día se me hace un año hasta veros, porque en esta vida no tengo otro descanso sino a vos, ni tengo otro deseo. Y a mi hijo Antón de Blas le dad mis besamanos y lo abrazad y le digáis que lo estoy esperando por horas a vos y a él, os estoy esperando por horas. No tengo más que deciros, sino que Nuestro Señor Dios os traiga con bien como yo deseo. De esta Nueva España, a do quedo, a primero del mes de noviembre. Señora, a vuestro padre y madre y a nuestros hermanos daréis mis besamanos.

Estas cartas que van con ésta v.m. las encamine a Jerez y v.m. (?) sin respuesta de estas cartas, que me va mucho en ello. Tórnolo a rogároslo, que no vengáis sin respuesta de ellas, porque me va la vida en ello. Y de mi hermano Juan Jiménez que me trae relación dónde está y cómo está. Yo os beso las manos,

Antonio de Blas

(A mi señora mujer Leonor Bernal, en Sanlúcar, mi señora) (I.G. 2050)

\section{BIBLIOGRAFIA}

ALBA, Victor: Historia social de la mujer, Barcelona, Ed. Plaza \& Janes, 1974.

ARIES, P. y DUBY, G.: Historia de la vida privada, Madrid, Taurus, 1988, vol. BURGUIERE, A.: H de la familia, Madrid, Alianza Editorial, 1988, tomo II.

MARAVALL, J.A.: Poder, honor y élites en el s. XVII, Madrid, Ed. siglo veintiuno, 1984.

MARTINEZ, J.L.: Pasajero de Indias, Madrid, Alianza Editorial, 1983.

OT'TE, Enrique: Cartas privadas de emigrantes a Indias, 1540-1516.

SANCHEZ ORTEGA, Elena: "La mujer en el antiguo régimen: Tipos históri$\cos$ y arquetipos literarios", en Nuevas perspectivas sobre la mujer, actas de las primeras jornadas de investigación interdisciplinaria organizadas por el Seminario de Estudios de la mujer de la Universidad Autónoma de Madrid, 1982.

VIGIL, Mariló: La vida de las mujeres en los siglos XVI y XVII, Madrid, Ed. siglo veintiuno, 1986. 